\title{
Impact of total thyroidectomy on quality of life at 6 months: the prospective ThyrQoL multicentre trial
}

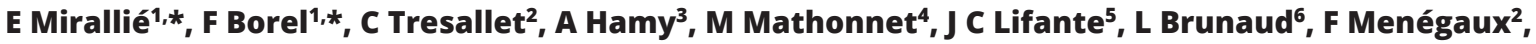 \\ J B Hardouin ${ }^{7,8}$ and C Blanchard ${ }^{1,9}$ on behalf of THYRQOL Group ${ }^{\dagger}$
}

${ }^{1}$ Chirurgie Cancérologique, Digestive et Endocrinienne, Hôtel Dieu, CHU Nantes, Place Alexis Ricordeau, Nantes Cedex 1, France, ${ }^{2}$ Chirurgie Générale, Viscérale et Endocrinienne, Hôpital Pitié-Salpêtrière, AP-HP, Sorbonne Universités Pierre et Marie Curie (Paris 6), Paris, France, ${ }^{3} \mathrm{CHU}$ Angers, Chirurgie Digestive et Endocrinienne, Angers Cedex 09, France, ${ }^{4}$ Chirurgie Digestive, Générale et Endocrinienne, CHU de Limoges - Hôpital Dupuytren, Limoges Cedex, France, ${ }^{5}$ Chirurgie Générale, Endocrinienne, Digestive et Thoracique, Centre Hospitalier Lyon-Sud, Pierre Bénite Cedex, France, ${ }^{6}$ Service de Chirurgie Digestive, Hépato-Biliaire, et Endocrinienne, CHU Nancy - Hôpital de Brabois, Nancy, France, ${ }^{7}$ UMR INSERM 1246-SPHERE, Université de Nantes, Université de Tours-Institut de Recherche en santé 2, Nantes, France, ${ }^{8}$ Plateforme de Méthodologie et de Biostatistique - DRCi - CHU de Nantes, Nantes, France, and 'Institut du Thorax, INSERM, CNRS, UNIV Nantes, Nantes, France

Correspondence should be addressed to C Blanchard Email

Claire.blanchard@chunantes.fr

\begin{abstract}
Objective: This study is to determine the impact of complications after total thyroidectomy on health-related quality of life (HR-QoL) and to identify significant predictive factors of HR-QoL changes. HR-QoL is usually impaired in patients with thyroid diseases compared to the general population. Thyroidectomy is largely performed in the case of benign thyroid benign and can be associated with long-term complications (vocal cord palsy, hypoparathyroidism). Design: The prospective ThyrQoL multicenter trial (NCT02167529) included 800 patients who underwent total thyroidectomy for benign or malignant non-extensive disease in seven French referral hospitals between 2014 and 2016.

Methods: HR-QoL was assessed using the MOS 36-item short form health survey (SF-36) self-questionnaire with a 6-month follow-up.

Results: We observed a significant improvement of HR-QoL 6 months after surgery $(P<0.0001)$. Postoperative complications were associated with a non-significant impairment of HR-QoL. In multivariable analysis, Graves' disease was associated with a significant improvement of HR-QoL $(O R=2.39$ [1.49; 3.84]) and thyroid malignant disease with an impairment of HR-QoL (OR $=1.44$ [0.99; 2.08]) after thyroidectomy. Conclusion: We observed a significant improvement of HR-QoL 6 months after total thyroid surgery for benign thyroid disease.
\end{abstract}

\section{Introduction}

Health-related quality of life (HR-QoL) is usually impaired in patients with thyroid diseases compared to the general population (1). Symptoms related to thyroid dysfunction,
(C) 2020 European Society of Endocrinology Printed in Great Britain compressive symptoms in the case of large goiter or orbitopathy in Graves' disease, or diagnosis of thyroid cancer may contribute to impair HR-QoL $(1,2)$. However, 
even in the absence of symptoms, HR-QoL deterioration is still observed (1).

Thyroidectomy for benign disease is the most commonly performed endocrine surgery worldwide. Patients are particularly concerned about the potential consequences of thyroid surgery on their HR-QoL (3). Despite favorable outcomes, especially in the case of benign thyroid diseases, thyroidectomy can be associated with long-term, postoperative complications, the most frequent ones being vocal cord palsy (VCP) and hypoparathyroidism. Their incidence varies respectively from 0.5 to $20 \%$ and from 19 to $38 \%(4,5,6)$. Even in patients without complications, thyroidectomy may have a significant impact on daily life due to lifetime hormonal replacement $(2,7)$ or discomfort caused by persistent functional voice or swallowing symptoms $(8,9)$.

Hypoparathyroidism and voice disorders have been associated with HR-QoL impairment $(9,10,11)$. Hormonal changes may also be involved in postoperative HR-QoL, especially because the adequate restoration of previous thyroid function is difficult to assess (7). The optimization of HR-QoL should be a main objective, especially in patients for whom the efficacy of the treatment is difficult to assess according to standard criteria.

The aims of this study were (1.) to determine the impact of complications after total thyroidectomy on HR-QoL in a large population and (2.) to identify significant predictive factors of HR-QoL changes.

\section{Methods}

\section{Study design}

From September 2014 to December 2016, patients with benign or non-extensive malignant thyroid pathologies, scheduled to undergo total thyroidectomy in seven French referral centers (Angers University Hospital, Limoges University Hospital, Nancy Regional University Hospital, Nantes University Hospital, Pitié-Salpêtrière Hospital, South Lyon Hospital Complex, and Vendée Hospital Centre), were prospectively included in this single-arm study. Exclusion criteria were age under 18 years, pregnancy or breastfeeding, suspected or confirmed medullary thyroid cancer, clinically and/or radiologically enlarged cervical lymph node(s), and preoperative voice disorders with confirmed VCP (Fig. 1).

The national committee 'Commission Nationale Informatique et Libertés' (CNIL) and the local ethics committees 'Comité Consultatif sur le Traitement de l'Information en Matière de Recherche' (CCTIRS) and 'Groupe Nantais d'Ethique dans le Domaine de la Santé' (GNEDS) approved this study (CNIL \#914165; CCTIRS \#14.105; GNEDS \#2012-06-07). All patients provided signed informed consent before surgery. The study is registered with ClinicalTrials.gov number NCT02167529, as the 'Quality of Life after Thyroidectomy (ThyrQoL)' study.

\section{Procedures}

Surgery was performed under general anesthesia with tracheal intubation. The surgical procedure consisted of extracapsular total thyroidectomy through a collar incision with a midline opening of the fascia. The strap muscles were not cut unless required. Accurate dissection close to thyroid capsule and single ligatures of superior lobe vessels were performed in order to preserve the external branch of superior laryngeal nerve. Recurrent laryngeal nerves (RLNs) were routinely identified and preserved, possibly with the help of intraoperative neuromonitoring (IONM, Medtronic ${ }^{\circledR}$, Jacksonville, FL, USA), the use of which was left to the surgeon's choice. Lymph node dissection (central neck dissections only) was performed if malignant disease was suspected preoperatively or on frozen section. The decision of node dissection was made intraoperatively by the surgeon according to her/his habits. Drainage was left to the discretion of the surgeons. Replacement therapy with levothyroxine was introduced on the day after surgery, according to each center standard protocol. For RAI therapy dose, patients with T2N1a had $100 \mathrm{mCi}$; the rest of the cancer patients (T1NO, T1N1 and T2N0) had $30 \mathrm{mCi}$.

\section{Outcome variables}

Demographic, clinical, and biological (calcium, TSH) data were prospectively collected during the preoperative period and second and sixth months after surgery.

Plasma levels of calcium were measured on the day after surgery. Measurements were repeated if serum calcium was $<2 \mathrm{mmol} / \mathrm{L}(80 \mathrm{mg} / \mathrm{L})$ on postoperative day 2, along with the measurement of parathyroid hormone level (PTH). Hypoparathyroidism was defined by a postoperative serum calcium $<2 \mathrm{mmol} / \mathrm{L}$ and requirement for calcium and/or vitamin D supplementation. It was defined as transient if solved within 6 months after surgery and permanent if persistent beyond 6 months after surgery. 
Patient scheduled for total thyroidectomy

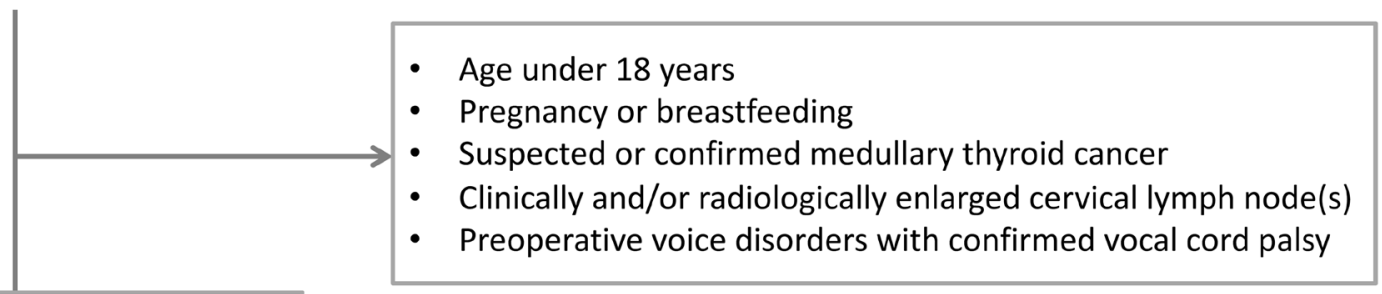

- Benign nodular goiter

- Graves' disease

- Nodule with Bethesda IV cytology

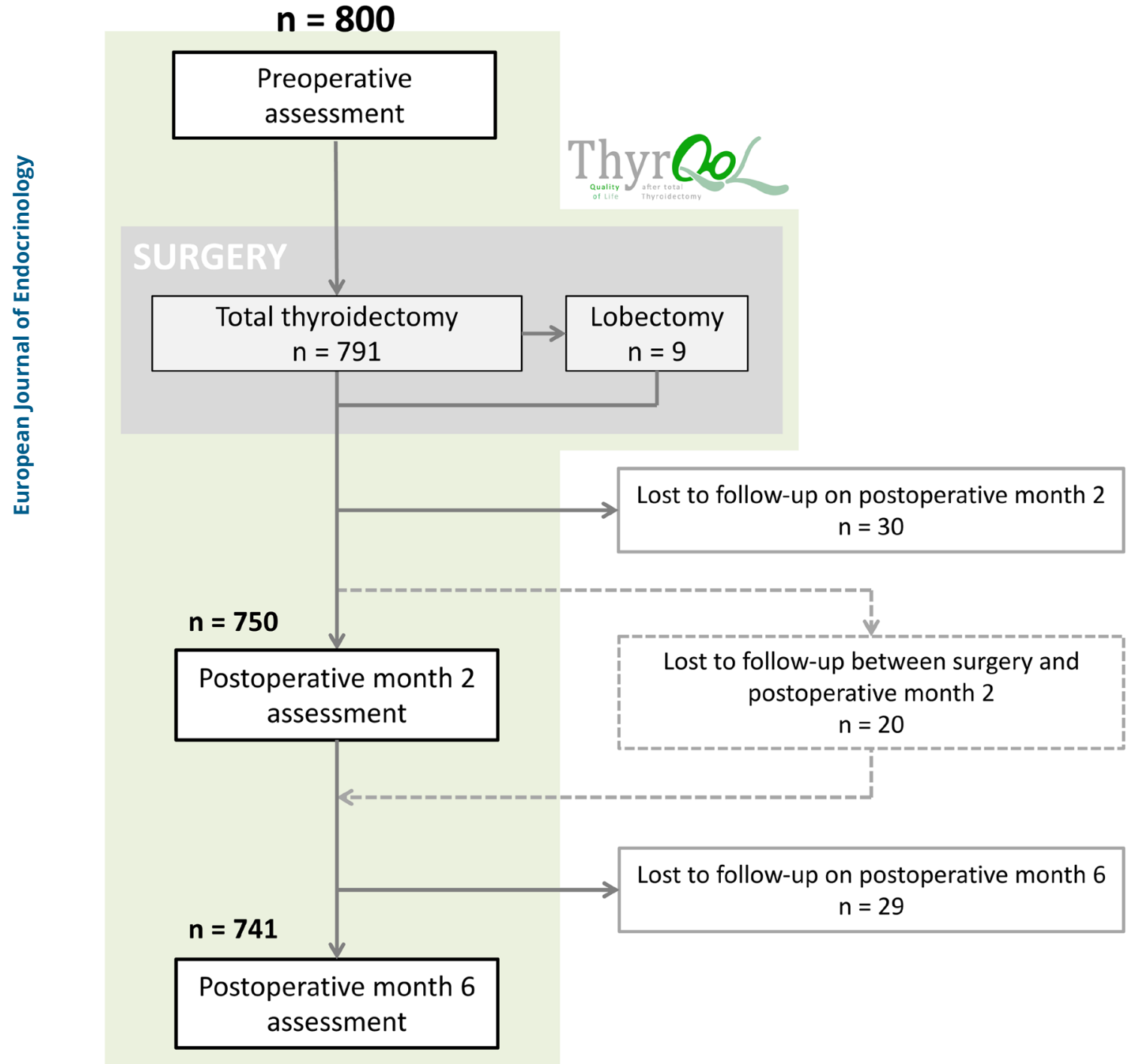

\section{Figure 1}

Flowchart for the trial (ClinicalTrials.gov NCT02167529). A full color version of this figure is available at https://doi.org/10.1530/ EJE-19-0587. 
Pre- and postoperative laryngeal examinations were not systematic but performed only in the case of voice abnormality. VCP was defined as transient if solved within 6 months after surgery and permanent if persistent beyond 6 months after surgery.

Preoperative self-questionnaires were given to the patients during the preoperative consultation and collected at admission; postoperative self-questionnaires were sent to the patients and returned by mail 2 and 6 months after surgery.

\section{HR-QoL assessment}

The MOS 36-item short form health survey (SF-36) was used to assess pre- and postoperative HR-QoL. The SF-36 questionnaire is the most extensively used and validated generic instrument for measuring HR-QoL (12), including after thyroid surgery $(13,14,15)$. It has been validated in its French translated version (16).

The SF-36 is a self-administrated questionnaire containing 36 items that describe eight dimensions of health: physical functioning (PF), social functioning (SF), role limitations due to physical problems (role physical $-\mathrm{RP})$, bodily pain (BP), general mental health $(\mathrm{MH})$, role limitations due to emotional problems (role emotional - RE), vitality (VT), and general health perception (GH) (17). Two summary scores can be computed: physical (PCS) and mental (MCS). All dimension and summary scores are scaled from 0 to 100 , the higher the score the better the HR-QoL is. Variations of at least 5 and 2.5 points were considered as the minimally, clinically important differences for dimension and composite scores respectively (18).

\section{Statistical analysis}

The primary endpoint was defined as the variation of the mental health score of the SF-36 questionnaire between preoperative visit and postoperative month 6 . MH score was chosen because we estimated that postoperative morbidity should have a greater impact on mental condition than on physical state.

Based on an expected incidence of complications between $3 \%$ and $4 \%$ at postoperative month 6 and an effect size on an anxiety scale between patients with and without complications estimated at 0.5 according to literature, calculations showed that 780 patients should be included to achieve a power of $80 \%$ and significance level of 0.05 (19).
We compared SF-36 scores between each endpoint using the ratio between patients' scores and the published reference scores of a sex- and age-matched French reference population (20). This ratio represents the percentage of the expected scores obtained by the patients, the expected scores being those of individuals of the same gender and age category, representative of the French general population. By definition, the general population has a mean ratio of $100 \%$.

Statistical analysis was performed following the intention to treat principle: statistical analyses are realized on all the included patients. Univariable analysis was performed using two-sample $t$-tests and $\chi^{2}$ tests for continuous and categorical variables respectively. Multivariable analysis was performed using logistic regression. Statistical analyses were performed using the Stata software version 15 (StataCorp). Multivariable analysis was performed using logistic regression. All the significant variables at 25\% were retained for this multivariate analysis, and then the variables not significant at $5 \%$ have been dropped one by one (Stepwise procedure). Graphics were made using Microsoft Excel version 14 (Microsoft Corporation).

\section{Results}

\section{Patients' characteristics and perioperative status}

Eight hundred patients were enrolled and included in this study. Their perioperative characteristics are summarized in Table 1. The most frequent surgical indication was benign nodular goiter (69\%) (Fig. 1).

The classification of malignant tumor was $\mathrm{T} 1 \mathrm{NO}$ for 116 patients, T1N1 for 36 patients, T2NO for 11 patients, and T2N1 for 27 patients. None were T3 or T4 or M1 in TNM classification. Seven hundred and ninety-one patients (99\%) underwent total thyroidectomy, while nine (1\%) had lobectomy, because of IONM signal loss after the resection of the first lobe (decision made intraoperatively by the surgeon).

\section{HR-QoL evolution after surgery}

Seven hundred and twenty-one patients (90\%) completed the three SF-36 questionnaires. Forty-nine patients (6\%) completed two SF-36 questionnaires including the preoperative questionnaire. Thirty patients (4\%) completed only one questionnaire (Fig. 2 and Table 2). 
Table 1 Patients characteristics and perioperative outcomes, $n=800$.

\begin{tabular}{|c|c|}
\hline Characteristics & Values \\
\hline \multicolumn{2}{|l|}{ Patients' characteristics } \\
\hline \multicolumn{2}{|l|}{ Gender, $n(\%)$} \\
\hline Male & $144(18)$ \\
\hline Female & $656(82)$ \\
\hline \multicolumn{2}{|l|}{ Surgical indication, $n(\%)$} \\
\hline Benign nodular goiter & $556(69.5)$ \\
\hline Graves' disease & $112(14)$ \\
\hline Nodule with Bethesda IV cytology & $54(6.75)$ \\
\hline Other $^{\dagger}$ & $78(9.75)$ \\
\hline \multicolumn{2}{|l|}{ Surgery, $n(\%)$} \\
\hline Total thyroidectomy & 791 (98.9) \\
\hline Unilateral lobectomy & $9(1.1)$ \\
\hline Use of IONM & $473(59.1)$ \\
\hline Unilateral IONM loss of signal & $43(9.1)$ \\
\hline Associated lymph node dissection & $88(11)$ \\
\hline Associated parathyroid procedure & $93(11.6)$ \\
\hline \multicolumn{2}{|l|}{ Histological diagnosis, $n(\%)$} \\
\hline Benign thyroid disease & $610(76.25)$ \\
\hline Malignant tumor* & $190(23.75)$ \\
\hline Papillary thyroid cancer & $161(84.7)$ \\
\hline Follicular thyroid cancer & $27(14.2)$ \\
\hline Other $^{\Delta}$ & $9(4.7)$ \\
\hline Multiple malignant tumors & $71(37.4)$ \\
\hline Tumor size", mm; median $\left[\mathrm{Q}_{1} ; \mathrm{Q}_{3}\right]$ & $9[3 ; 16]$ \\
\hline $\mathrm{N}+$ & $26(13.7)$ \\
\hline Associated thyroiditis & 207 (25.9) \\
\hline Thyroid weight, (g); median $\left[\mathrm{Q}_{1} ; \mathrm{Q}_{3}\right]$ & $30.8[20 ; 55]$ \\
\hline \multicolumn{2}{|l|}{ Postoperative outcomes } \\
\hline \multicolumn{2}{|l|}{ Immediate postoperative complications, $n$ (\%) } \\
\hline Re-operation for hematoma ${ }^{c}$ & $11(1.4)$ \\
\hline Transient VCPS & $36(4.5)$ \\
\hline Transient hypoparathyroidism ${ }^{\ddagger}$ & $87(10.9)$ \\
\hline $\begin{array}{l}\text { Mean hospital length stay, (day) } \\
\text { mean } \pm \text { S.D. }\end{array}$ & $1.88 \pm 3.7$ \\
\hline $\begin{array}{l}\text { Median off-work duration, (day) median } \\
{\left[\mathrm{Q}_{1} ; \mathrm{Q}_{3}\right]}\end{array}$ & $25[18 ; 35]$ \\
\hline \multicolumn{2}{|l|}{ Long-term postoperative complications, $n(\%)$} \\
\hline Permanent VCP\# & $6(0.8)$ \\
\hline Permanent hypoparathyroidism ${ }^{\S}$ & $44(5.5)$ \\
\hline
\end{tabular}

${ }^{\dagger}$ Prophylactic thyroidectomy for familial history of medullary thyroid cancer, iatrogenic dysthyroidism, unspecified; *Seven patients had two different tumor types; ${ }^{\Delta}$ Medullary thyroid cancer $(n=3)$, Thyroid metastasis $(n=2)$, Solitary fibrous tumor $(n=1)$, Thyroid tumor of uncertain malignant potential $(n=1)$, Thyroid oncocytic tumor $(n=1)$, Unspecified tumor $(n=1)$; "Mean tumor size considering the largest tumor; ' $\mathrm{Re}$-operation for bleeding or compressive hematoma during the first $24 \mathrm{~h}$ postoperatively; $\int$ Postoperative VCP solved within 6 months after the surgery; \#Postoperative VCP persisting 6 months after the surgery; ${ }^{\ddagger}$ Hypocalcaemia $<2 \mathrm{mmol} / \mathrm{L}$ at hospital discharge; ${ }^{5}$ Need for calcium and/or vitamin D supplements on postoperative month 6 . IONM, intraoperative neuromonitoring; TSH, thyroid Stimulating Hormone; VCP, vocal cord palsy.

SF-36 score ratios were higher 2 months after surgery for $\mathrm{GH}(94 \%$ vs $91 \% ; P=0.0112)$ and $\mathrm{MH}(92 \%$ vs $87 \% ; P<0.0001)$, showing improved $\mathrm{QoL}$ in these domains (Table 2). At the 6-month evaluation, all the ratios were significantly higher than those obtained at the preoperative visit, reflecting improved QoL in all SF-36 QoL domains (Fig. 2 and Table 2). In absolute terms, differences between preoperative and 6-month score were clinically relevant ( $>5$ points) for emotional domains (SF, RE) but not for physical domains.

\section{HR-Qol evolution compared to the general French population}

Compared to the sex- and age-matched French reference population, SF-36 scores were significantly lower in our population in almost all domains, both before and after surgery (Table 3).

\section{Factors associated with HR-QoL significant changes}

No statistically significant differences in SF-36 dimension or composite scores were observed, neither between patients with or without permanent hypoparathyroidism (Fig. 3) nor between patients with or without permanent VCP 6 months after surgery.

In bivariate analysis, thyroidectomy for Graves' disease $(P<0.0001)$, thyroid weight $(P=0.0281)$, and diagnosis of thyroid malignant tumor $(P=0.017)$ were associated with significant changes of the SF-36 MH score at the 6-month evaluation, defined by a variation of 5 points or more (Table 4). In multivariable analysis, age, sex, BMI, thyroidectomy for Graves' disease, thyroid weight, and diagnosis of malignant tumor were tested. In multivariable analysis, thyroidectomy for Graves' disease remained significantly associated with an improvement of the $\mathrm{MH}$ score 6 months after surgery $(\mathrm{OR}=2.39$ [1.49; 3.84]). There was a trend toward the impairment of the $\mathrm{MH}$ score in patients diagnosed with thyroid malignant tumor $(\mathrm{OR}=1.44$ [0.99; 2.08]). Interestingly, complications were significantly more frequent in patients with lymph node dissection: $15 \%$ vs $6 \%$ at month $2(P=0.002)$ and $15 \%$ vs $5 \%$ at month $6(P<0.001)$.

\section{Impact of total thyroidectomy on professional activity}

Median off-work duration after total thyroidectomy was 25 days $[18 ; 35]$.

It significantly increased in the case of postoperative complications (42 days [30; 73] vs 24 days [18; 34]; $P=0.0003)$. Permanent VCP (112 days $[44 ; 180] ; P=0.0468)$ 


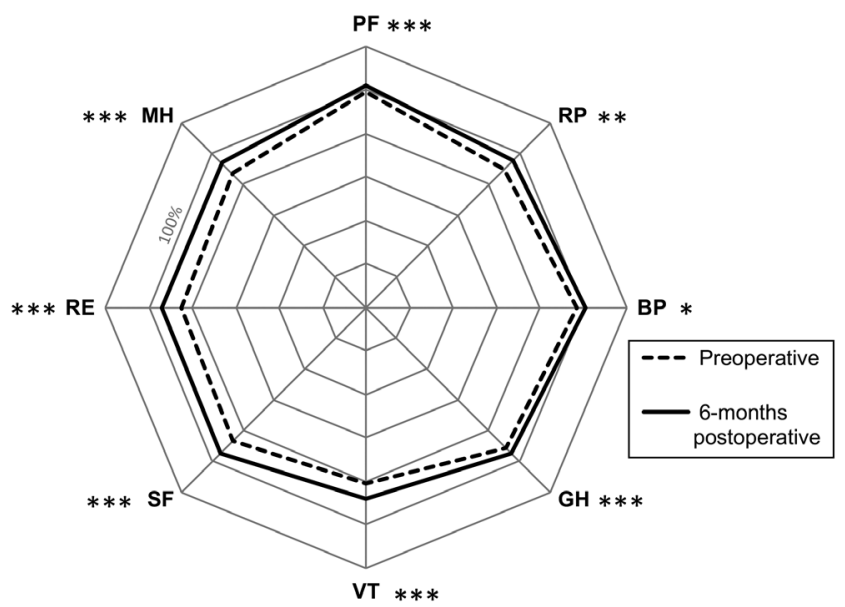

Figure 2

Evolution of SF-36 ratios on postoperative month 6 (ratio between the score of the population of the study and a French reference population matched on age and sex).

and permanent hypoparathyroidism (46 days [30; 76]; $P=0.0014)$ both specifically increased off-work period significantly compared to patients without permanent complications.

\section{Discussion}

This prospective multicenter observational study (without intervention - patients received standard care, i.e. thyroidectomy for thyroid disease) reports statistically significant improvement in HR-QoL after total thyroidectomy for benign thyroid diseases, using the validated questionnaire SF-36 at 6 months. This improvement, observed in all the eight measured domains of HR-QoL, was more important for mental health scores.
These results are similar to those found in the literature $(21,22,23,24,25,26,27,28)$.

At the second postoperative month evaluation, a statistically significant improvement was already observed for $\mathrm{GH}$ and $\mathrm{MH}$ scores, whereas the RP score was significantly decreased, before increasing above baseline values at month 6 . Sorensen et al. showed similar evolution patterns in HR-QoL evolution after surgery, but with an initial improvement more marked and persistent up to postoperative month (28). Generally, the worse the preoperative HR-QoL, the more important the HR-QoL improvement was $(23,24,25,26,27,28)$.

Preoperative HR-QoL was significantly impaired in our population compared to a French referral population. Despite significant improvements after surgery, postoperative HR-QoL remained impaired compared to the general population. The improvement seemed to be more important in mental domains as measured by SF-36, compared to physical domains. We have no formal explanation for the difference of HR-QoL between the general population and 6-month post thyroidectomy patients. We may hypothesize that our follow-up is too short to observe a 'normal' HR-QoL after thyroidectomy. Most of the studies also find a persistent impairment compared to general population. Some studies described an improvement in HR-QoL after surgery up to general population levels; the longer the follow-up, the more the HR-QoL tends to be close to that of general population $(29,30,31)$.

The most relevant factor influencing HR-QoL improvement was Graves' disease. Other studies report the improvement of HR-QoL after surgery for Graves' disease, but the superiority of surgery compared to medical treatment or iodine therapy has not been

Table 2 Evolution of SF-36 scores: ratios between the scores of our study population and those of the French reference population matched on age and sex.

\begin{tabular}{|c|c|c|}
\hline SF-36 scores & Before surgery $(\%)$ & 2 months after surgery $(\%)$ \\
\hline PF & 99 & 100 \\
\hline RP & 90 & 81 \\
\hline BP & 97 & 100 \\
\hline $\mathrm{GH}$ & 91 & 94 \\
\hline VT & 81 & 79 \\
\hline SF & 87 & 89 \\
\hline RE & 85 & 84 \\
\hline $\mathrm{MH}$ & 87 & 92 \\
\hline PCS & 99 & 99 \\
\hline MCS & 88 & 89 \\
\hline
\end{tabular}

\begin{tabular}{cc}
\hline \multicolumn{1}{c}{} \\
\hline 0.49 \\
$<\mathbf{0 . 0 0 0 1}$ \\
0.054 \\
$\mathbf{0 . 0 1 1 2}$ \\
0.14 \\
0.32 \\
0.48 \\
$<\mathbf{0 . 0 0 0 1}$ \\
$\mathbf{0 . 0 1 9 0}$ \\
0.087 \\
\hline
\end{tabular}

\begin{tabular}{c}
\hline months after surgery $(\%)$ \\
\hline 102 \\
96 \\
101 \\
95 \\
88 \\
95 \\
94 \\
94 \\
101 \\
94 \\
\hline
\end{tabular}

\begin{tabular}{c}
\hline $\boldsymbol{P}$ \\
\hline $\mathbf{0 . 0 0 0 3}$ \\
$\mathbf{0 . 0 0 3 9}$ \\
$\mathbf{0 . 0 1 3 2}$ \\
$\mathbf{0 . 0 0 0 2}$ \\
$<\mathbf{0 . 0 0 0 1}$ \\
$<\mathbf{0 . 0 0 0 1}$ \\
$<\mathbf{0 . 0 0 0 1}$ \\
$<\mathbf{0 . 0 0 0 1}$ \\
0.20 \\
$<\mathbf{0 . 0 0 0 1}$
\end{tabular}

A ratio of $100 \%$ reflects a similarity in our population and in the reference population. $\mathrm{BP}$, bodily pain; GH, general health perception; MCS, mental composite score; $\mathrm{MH}$, general mental health; PCS, physical composite score; PF, physical functioning; RE, role-emotional; RP, role-physical; SF, social functioning; VT, vitality. 
Table 3 Comparison of SF-36 scores between the study population and the French reference population matched on age and sex, before surgery, at month 2 and at month 6.

\begin{tabular}{|c|c|c|c|}
\hline SF-36 scores & ThyrQoL population (mean \pm S.D.) & $\begin{array}{l}\text { Ratio of the scores to the sex- and age-matched French } \\
\text { reference population (mean } \pm \text { S.D.) }\end{array}$ & $P$ \\
\hline \multicolumn{4}{|l|}{ Preoperative } \\
\hline $\mathrm{PF}$ & $81.8 \pm 20.35$ & $99 \% \pm 26 \%$ & 0.0145 \\
\hline $\mathrm{RP}$ & $72.32 \pm 36.79$ & $90 \% \pm 48 \%$ & $<0.0001$ \\
\hline $\mathrm{BP}$ & $69.19 \pm 26.16$ & $97 \% \pm 37 \%$ & 0.0063 \\
\hline $\mathrm{GH}$ & $61.95 \pm 19.77$ & $91 \% \pm 30 \%$ & $<0.0001$ \\
\hline VT & $47.65 \pm 21.51$ & $81 \% \pm 37 \%$ & $<0.0001$ \\
\hline SF & $70.17 \pm 25.27$ & $87 \% \pm 32 \%$ & $<0.0001$ \\
\hline RE & $68.32 \pm 38.03$ & $85 \% \pm 48 \%$ & $<0.0001$ \\
\hline $\mathrm{MH}$ & $58.4 \pm 20.74$ & $87 \% \pm 31 \%$ & $<0.0001$ \\
\hline PCS & $49.51 \pm 8.62$ & $99 \% \pm 18 \%$ & 0.1960 \\
\hline MCS & $41.79 \pm 11.5$ & $88 \% \pm 24 \%$ & $<0.0001$ \\
\hline \multicolumn{4}{|c|}{ Postoperative month 2} \\
\hline PF & $82.57 \pm 19.59$ & $100 \% \pm 25 \%$ & 0.2377 \\
\hline $\mathrm{RP}$ & $64.36 \pm 40.43$ & $81 \% \pm 53 \%$ & $<0.0001$ \\
\hline $\mathrm{BP}$ & $71.09 \pm 24.41$ & $100 \% \pm 36 \%$ & 0.6327 \\
\hline $\mathrm{GH}$ & $63.77 \pm 20.16$ & $94 \% \pm 31 \%$ & $<0.0001$ \\
\hline VT & $46.69 \pm 21.28$ & $79 \% \pm 37 \%$ & $<0.0001$ \\
\hline SF & $71.47 \pm 24.98$ & $89 \% \pm 32 \%$ & $<0.0001$ \\
\hline $\mathrm{RE}$ & $67.31 \pm 40.1$ & $84 \% \pm 51 \%$ & $<0.0001$ \\
\hline $\mathrm{MH}$ & $61.64 \pm 19.87$ & $92 \% \pm 30 \%$ & $<0.0001$ \\
\hline PCS & $48.96 \pm 8.24$ & $99 \% \pm 18 \%$ & 0.0046 \\
\hline MCS & $42.55 \pm 11.75$ & $89 \% \pm 25 \%$ & $<0.0001$ \\
\hline \multicolumn{4}{|c|}{ Postoperative month 6} \\
\hline $\mathrm{PF}$ & $84.13 \pm 20.34$ & $102 \% \pm 26 \%$ & 0.2687 \\
\hline $\mathrm{RP}$ & $76.65 \pm 35.23$ & $96 \% \pm 46 \%$ & 0.0007 \\
\hline $\mathrm{BP}$ & $71.94 \pm 25.76$ & $101 \% \pm 36 \%$ & 0.5912 \\
\hline $\mathrm{GH}$ & $64.55 \pm 20.57$ & $95 \% \pm 31 \%$ & $<0.0001$ \\
\hline VT & $51.88 \pm 20.51$ & $88 \% \pm 35 \%$ & $<0.0001$ \\
\hline SF & $76.05 \pm 23.3$ & $95 \% \pm 29 \%$ & $<0.0001$ \\
\hline \multirow[t]{2}{*}{$\mathrm{RE}$} & $75.45 \pm 37.02$ & $94 \% \pm 47 \%$ & $<0.0001$ \\
\hline & & $94 \% \pm 29 \%$ & \\
\hline $\mathrm{MH}$ & $63.1 \pm 19.46$ & $94 \% \pm 29 \%$ & $<0.0001$ \\
\hline PCS & $50.01 \pm 8.66$ & $101 \% \pm 18 \%$ & 0.4308 \\
\hline MCS & $44.61 \pm 10.94$ & $94 \% \pm 23 \%$ & $<0.0001$ \\
\hline
\end{tabular}

$\mathrm{BP}$, bodily pain; GH, general health perception; $\mathrm{MCS}$, mental composite score; $\mathrm{MH}$, general mental health; PCS, physical composite score; PF, physical functioning; RE, role-emotional; RP, role-physical; SF, social Functioning; VT, Vitality.

proven $(32,33)$. Graves' disease has been shown to be associated with particularly impaired HR-QoL, which could explain these good results $(1,23)$.

In contrast, we found that the diagnosis of malignant tumor was associated with postoperative HR-QoL impairment. The knowledge of having thyroid cancer can impair HR-QoL, although these tumors usually have favorable long-term prognosis $(34,35)$. Adjuvant iodine therapy could be implicated in this impairment, even though we did not report iodine therapy as a significant factor of HR-QoL modification. The 6-month duration of follow-up in our study could also explain this result, as studies with longer follow-up periods report the improvement of HR-QoL after thyroid surgery for malignant disease $(29,31)$.
But several other studies showed that even years after initial therapy, thyroid cancer survivors still have a decreased QoL $(36,37,38,39)$. We may hypothesize that the higher rate of complications in patients who underwent lymph node dissection ( $15 \%$ vs $5 \%$ at month 6) could explain this impairment.

We did not find a statistically significant impact of postoperative complications on HR-QoL. Postoperative complications had a negative impact on HR-QoL, although decrease of SF-36 scores after complication did not reach significance. Professional activity was significantly impaired by complications, leading to a doubled off-work period in our study. Work ability and HR-QoL have been proved to be closely related, suggesting a relevant impact of complications after total 


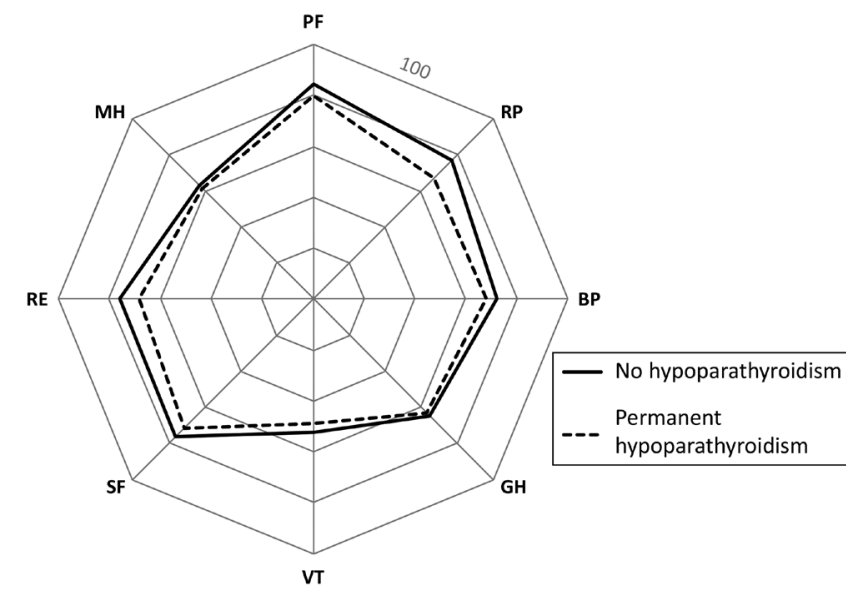

Figure 3

Comparison of SF-36 scores on postoperative month 6 between patients without complication and patients with hypoparathyroidism (differences were not statistically significant).

thyroidectomy (40). Off-work period was 10 days longer than that recommended in France; meanwhile, standard off-work period at hospital discharge was 3 weeks. It suggests that more than half of our patients felt the need for extended work stoppage.

We report a non-significant decrease of all the SF-36 scores at 6 months in the case of permanent hypoparathyroidism. All the studies that investigated the relationships between HR-QoL and hypoparathyroidism reported a significant impairment of HR-QoL, irrespective of the cause of hypoparathyroidism $(41,42,43)$. Standard treatment of hypoparathyroidism, consisting of calcium and vitamin D supplementation, does not allow the substitution of the missing hormone or the restoration of normal phospho-calcic metabolism. Moreover, PTH receptor located in the CNS could be implied (44). Supplementation with 1-84 PTH has shown good results in HR-QoL improvement (45).

VCP was not associated with HR-QoL modification in our study although vocal impairment is traditionally associated with diminished HR-QoL $(46,47)$. Spector et al. reported HR-QoL impairment in the case of VCP (10). However, the impact of voice alteration on HR-QoL is highly variable across patients $(48,49)$. The use of IONM, leading to lobectomy rather than thyroidectomy in case of loss of signal, could have avoided bilateral VCP, which could have severely impaired HR-QoL.

We did not find a significant effect of hormonal balance on HR-QoL. These results are similar to those of literature, in which no significant impact of hormonal substitution has been shown on HR-QoL (49, 50, 51, $52,53)$. However, the serum TSH levels defining hormonal balance are debated and no protocol of hormonal substitution has shown superiority $(54,55)$.

The main limitation of our study could be the choice of a generic rather than a disease-specific questionnaire of HR-QoL (33). Thyroid-specific patient reported outcome (ThyPRO), the most commonly used specific questionnaire to assess HR-QoL in thyroid diseases, has been described as more sensitive than SF-36 for therapeutic evaluation (56). HR-QoL modifications, more pronounced with ThyPRO than with SF-36, might have shown more meaningful results $(26,27)$. However, we believe that SF-36 score allows a general QoL evaluation, regardless of the underlying thyroid disease or specific thyroidectomy-related morbidity. It has also the advantage to be the most extensively used and validated generic instrument for measuring HR-QoL (12). Moreover, SF-36 has been validated in French, which is not the case of the ThyPRO questionnaire.

Another limitation is the heterogeneity of the included patients with benign goiters, small cancers, and Graves' diseases. The management of thyroid cancer, including lymph node dissection and iodine therapy, significantly differs from the management of benign disease. Anymore, the clinical impact of Graves' disease and benign goiter is different. The underlying disease may override postoperative complications.

The relatively high rate of permanent hypoparathyroidism, defined by the need of calcium and/or vitamin D supplementation, can be questioned. Some physicians may maintain patients with treatments, regardless of it formally required.

Another limitation is due to the absence of systematic postoperative vocal cords examination. This may underestimate our permanent VCP rate. Finally, because of too many missing data, the impact of RAI therapy on QoL could not be evaluated in our series.

Moreover, we did not study the impact of quality of wound healing or swallowing disorders after surgery, which could be a confounding factor (8). Our results are supported by a large population and mostly by an excellent follow-up on postoperative month 6 .

Most patients with thyroid disease experience significantly impaired HR-QoL. Our results, issued from a large multicenter prospective study, show a significant improvement of HR-QoL after total thyroid surgery for benign athyroid disease. However, postoperative HR-QoL scores did not reach those of a reference sex- and agematched population. Postoperative complications did not impair significantly the HR-QoL changes. Thyroidectomy 
Table 4 Factors associated with a significant modification of postoperative MH score at postoperative month 6 (bivariate analysis).

\begin{tabular}{|c|c|}
\hline Characteristics & $\begin{array}{c}\text { MH score decrease } \geq \mathbf{5} \\
(n=205)(28 \%)\end{array}$ \\
\hline Age, mean \pm S.D. (year) & $52.7 \pm 13.2$ \\
\hline \multicolumn{2}{|l|}{ Sex } \\
\hline Male & $22 \%$ \\
\hline Female & $78 \%$ \\
\hline \multicolumn{2}{|l|}{ BMI } \\
\hline $\mathrm{BMI}<18 \mathrm{~kg} / \mathrm{m}^{2}$ & $3 \%$ \\
\hline BMI $18-25 \mathrm{~kg} / \mathrm{m}^{2}$ & $42 \%$ \\
\hline BMI $25-30$ kg/m² & $30 \%$ \\
\hline $\mathrm{BMI} \geq 30 \mathrm{~kg} / \mathrm{m}^{2}$ & $25 \%$ \\
\hline \multicolumn{2}{|l|}{ Professional activity } \\
\hline Active worker & $65 \%$ \\
\hline Unemployed & $35 \%$ \\
\hline \multicolumn{2}{|l|}{ Preoperative THS level } \\
\hline Serum TSH $<0.2 \mu \mathrm{UI} / \mathrm{L}$ & $14 \%$ \\
\hline Serum TSH 0.2-4 $\mu \mathrm{UI} / \mathrm{L}$ & $82 \%$ \\
\hline Serum TSH > $4 \mu \mathrm{UI} / \mathrm{L}$ & $4 \%$ \\
\hline \multicolumn{2}{|l|}{ Surgical indication } \\
\hline Benign nodular goiter & $81 \%$ \\
\hline Graves' disease & $4 \%$ \\
\hline Nodule Bethesda IV & $7 \%$ \\
\hline Other* & $8 \%$ \\
\hline Associated lymph node dissection & $12 \%$ \\
\hline Associated parathyroid procedure ${ }^{\dagger}$ & $14 \%$ \\
\hline Re-operation for hematoma & $2 \%$ \\
\hline Permanent hypoparathyroidism ${ }^{\S}$ & $6 \%$ \\
\hline Permanent VCP ${ }^{\ddagger}$ & $<1 \%$ \\
\hline Malignant tumor & $32 \%$ \\
\hline Associated thyroiditis & $26 \%$ \\
\hline Thyroid weight, mean \pm S.D. (g) & $75.3 \pm 19.2$ \\
\hline Postoperative radioactive iodine therapy & $17 \%$ \\
\hline $\begin{array}{l}\text { Euthyroidism at 6-month postoperative } \\
\text { (Serum TSH } 0.2-4 \mu \mathrm{UI} / \mathrm{L})\end{array}$ & $73 \%$ \\
\hline
\end{tabular}

\begin{tabular}{|c|c|c|}
\hline $\begin{array}{c}\text { Stable MH score }(\Delta \mathrm{MH} \leq 5) \\
(n=189)(26 \%)\end{array}$ & $\begin{array}{c}\text { MH score increase } \geq \mathbf{5} \\
\quad(n=340)(46 \%)\end{array}$ & $\mathbf{P}$ \\
\hline $52.8 \pm 12.9$ & $50.4 \pm 13.4$ & $\begin{array}{l}0.052 \\
0.065\end{array}$ \\
\hline $21 \%$ & $15 \%$ & \\
\hline \multirow[t]{2}{*}{$79 \%$} & $85 \%$ & \\
\hline & & 0.15 \\
\hline $1 \%$ & $3 \%$ & \\
\hline $51 \%$ & $49 \%$ & \\
\hline $30 \%$ & $26 \%$ & \\
\hline \multirow[t]{2}{*}{$18 \%$} & $22 \%$ & \\
\hline & & 0.89 \\
\hline $67 \%$ & $66 \%$ & \\
\hline \multirow[t]{2}{*}{$33 \%$} & $34 \%$ & \\
\hline & & 0.26 \\
\hline $15 \%$ & $17 \%$ & \\
\hline $81 \%$ & $76 \%$ & \\
\hline \multirow{2}{*}{$4 \%$} & $7 \%$ & \\
\hline & & $<0.0001$ \\
\hline $73 \%$ & $66 \%$ & \\
\hline $12 \%$ & $19 \%$ & \\
\hline $7 \%$ & $6 \%$ & \\
\hline $8 \%$ & $9 \%$ & \\
\hline $13 \%$ & $9 \%$ & 0.37 \\
\hline $10 \%$ & $10 \%$ & 0.53 \\
\hline $2 \%$ & $1 \%$ & 0.44 \\
\hline $4 \%$ & $6 \%$ & 0.58 \\
\hline $1 \%$ & $1 \%$ & 0.88 \\
\hline $26 \%$ & $21 \%$ & 0.017 \\
\hline $27 \%$ & $28 \%$ & 0.86 \\
\hline $72.6 \pm 18.5$ & $71.6 \pm 18.8$ & 0.0281 \\
\hline $12 \%$ & $13 \%$ & 0.29 \\
\hline $72 \%$ & $75 \%$ & 0.76 \\
\hline
\end{tabular}

*Medullary thyroid cancer $(n=3)$, thyroid metastasis $(n=2)$, solitary fibrous tumor $(n=1)$, thyroid tumor of uncertain malignant potential $(n=1)$, thyroid oncocytic tumor $(n=1)$, unspecified tumor $(n=1)$; ${ }^{\dagger}$ Re-operation for bleeding or compressive hematoma during the first 24 hours postoperatively; "Associated parathyroidectomy and/or reimplantation; ${ }^{\S}$ Need for calcium and/or vitamin D supplements on postoperative month 6; ${ }^{\ddagger}$ Postoperative VCP persisting 6 months after the surgery.

$\mathrm{MH}$, General mental health.

for malignant disease was associated with an impairment of HR-QoL.

Our study may provide information to physicians and surgeons, to help them in choosing the most appropriate treatment; it may also help in providing the patients with better information on what to expect after total thyroidectomy in terms of HR-QoL, depending on their disease, especially in the case of Graves' disease.

\section{Declaration of interest}

The authors declare that there is no conflict of interest that could be perceived as prejudicing the impartiality of this study.

\section{Funding}

This research did not receive any specific grant from any funding agency in the public, commercial or not-for-profit sector.

\section{Acknowledgements}

The authors thank the THYRQOL group Catherine Ansquer, Emmanuelle Mourrain-Langlois and Anne Sophie Delemazure (CHU Nantes), Bastien Perrot (UMR INSERM 1246-SPHERE, Université de Nantes, Université de Tours), Mylène Longhi (CHU Pitié-Salpêtrière). THYRQOL Group: Claire Nominé (CHRU Nancy), Florent Espitalier, Delphine Drui, Cécile Caillard, Nelly Renaud-Moreau (CHU Nantes), Olivier Marret (CH la Roche sur-Yon), Stéphanie Mucci (CHU Angers), Niki Christou (CHU Limoges).

\section{References}

1 Bianchi GP, Zaccheroni V, Solaroli E, Vescini F, Cerutti R, Zoli M \& Marchesini G. Health-related quality of life in patients with thyroid disorders. Quality of Life Research 200413 45-54. (https://doi. org/10.1023/B:QURE.0000015315.35184.66)

2 McMillan C, Bradley C, Razvi S \& Weaver J. Evaluation of new measures of the impact of hypothyroidism on quality of life and symptoms: the ThyDQoL and ThySRQ. Value in Health $2008 \mathbf{1 1}$ 285-294. (https://doi.org/10.1111/j.1524-4733.2007.00232.x) 
3 Abdul-Sater L, Henry M, Majdan A, Mijovic T, Franklin JH, Brandt MG, Black MJ, Hier MP \& Payne RJ. What are thyroidectomy patients really concerned about? Otolaryngology: Head and Neck Surgery 2011144 685-690. (https://doi. org/10.1177/0194599811399556)

4 Duclos A, Peix JL, Colin C, Kraimps JL, Menegaux F, Pattou F, Sebag F, Touzet S, Bourdy S, Voirin N et al. Influence of experience on performance of individual surgeons in thyroid surgery: prospective cross sectional multicentre study. BMJ 2012344 d8041. (https://doi. org/10.1136/bmj.d8041)

5 Edafe O, Antakia R, Laskar N, Uttley L \& Balasubramanian SP. Systematic review and meta-analysis of predictors of postthyroidectomy hypocalcaemia. British Journal of Surgery 2014101 307-320. (https://doi.org/10.1002/bjs.9384)

6 Blanchard C, Pattou F, Brunaud L, Hamy A, Dahan M, Mathonnet M, Volteau C, Caillard C, Durand-Zaleski I, Mirallié E et al. Randomized clinical trial of ultrasonic scissors versus conventional haemostasis to compare complications and economics after total thyroidectomy (FOThyr). BJS Open 2017 2-10. (https://doi.org/10.1002/bjs5.2)

7 Stoll SJ, Pitt SC, Liu J, Schaefer S, Sippel RS \& Chen H. Thyroid hormone replacement after thyroid lobectomy. Surgery 2009 146 554-558; discussion 558-560. (https://doi.org/10.1016/j. surg.2009.06.026)

8 Lombardi CP, Raffaelli M, De Crea C, D'Alatri L, Maccora D, Marchese MR, Paludetti G \& Bellantone R. Long-term outcome of functional post-thyroidectomy voice and swallowing symptoms. Surgery 2009146 1174-1181. (https://doi.org/10.1016/j. surg.2009.09.010)

9 Borel F, Christou N, Marret O, Mathonnet M, Caillard C, Bannani S, Drui D, Espitalier F, Blanchard C \& Mirallié E. Long-term voice quality outcomes after total thyroidectomy: a prospective multicenter study. Surgery 2018163 796-800. (https://doi. org/10.1016/j.surg.2017.09.023)

10 Spector BC, Netterville JL, Billante C, Clary J, Reinisch L \& Smith TL. Quality-of-life assessment in patients with unilateral vocal cord paralysis. Otolaryngology: Head and Neck Surgery 2001125 176-182. (https://doi.org/10.1067/mhn.2001.117714)

11 Büttner M, Musholt TJ \& Singer S. Quality of life in patients with hypoparathyroidism receiving standard treatment: a systematic review. Endocrine 201758 14-20. (https://doi.org/10.1007/s12020017-1377-3)

12 Contopoulos-Ioannidis DG, Karvouni A, Kouri I \& Ioannidis JP. Reporting and interpretation of SF-36 outcomes in randomised trials: systematic review. BMJ 2009338 a3006. (https://doi.org/10.1136/ bmj.a3006)

13 Huang JK, Ma L, Song WH, Lu BY, Huang YB \& Dong HM. Quality of life and cosmetic result of single-port access endoscopic thyroidectomy via axillary approach in patients with papillary thyroid carcinoma. OncoTargets and Therapy 20169 4053-4059. (https://doi.org/10.2147/OTT.S99980)

14 Yue WW, Wang SR, Li XL, Xu HX, Lu F, Sun LP, Guo LH, He YP, Wang D \& Yin ZQ. Quality of life and cost-effectiveness of radiofrequency ablation versus open surgery for benign thyroid nodules: a retrospective cohort study. Scientific Reports 2016637838 . (https://doi.org/10.1038/srep37838)

15 Promberger R, Hermann M, Pallikunnel SJ, Seemann R, Meusel M $\&$ Ott J. Quality of life after thyroid surgery in women with benign euthyroid goiter: influencing factors including Hashimoto's thyroiditis. American Journal of Surgery 2014207 974-979. (https:// doi.org/10.1016/j.amjsurg.2013.05.005)

16 Perneger TV, Leplège A, Etter JF \& Rougemont A. Validation of a French-language version of the MOS 36-Item Short Form Health Survey (SF-36) in young healthy adults. Journal of Clinical Epidemiology 199548 1051-1060. (https://doi.org/10.1016/08954356(94)00227-h)
17 Ware JE \& Sherbourne CD. The MOS 36-item short-form health survey (SF-36). I. Conceptual framework and item selection. Medical Care 199230 473-483. (https://doi.org/10.1097/00005650199206000-00002)

18 Devilliers H, Amoura Z, Besancenot JF, Bonnotte B, Pasquali JL, Wahl D, Maurier F, Kaminsky P, Pennaforte JL, Magy-Bertrand N et al. Responsiveness of the 36-item Short Form Health Survey and the Lupus Quality of Life questionnaire in SLE. Rheumatology $2015 \mathbf{5 4}$ 940-949. (https://doi.org/10.1093/rheumatology/keu410)

19 Woisard V, Bodin S \& Puech M. The voice handicap index: impact of the translation in French on the validation. Revue de Laryngologie, Otologie, Rhinologie 2004125 307-312.

20 Perneger T, Leplège A \& Ecosse E. Le questionnaire MOS SF-36: manuel de l'utilisateur et guide d'interprétation des scores. Paris: Editions Estem, 2001.

21 Miccoli P, Minuto MN, Paggini R, Rucci P, Oppo A, Donatini G, Golia F, Novelli L, Carlini M \& Dell'Osso L. The impact of thyroidectomy on psychiatric symptoms and quality of life. Journal of Endocrinological Investigation 200730 853-859. (https://doi. org/10.1007/BF03349227)

22 Mishra A, Sabaretnam M, Chand G, Agarwal G, Agarwal A, Verma AK $\&$ Mishra SK. Quality of life (QoL) in patients with benign thyroid goiters (pre- and post-thyroidectomy): a prospective study. World Journal of Surgery 201337 2322-2329. (https://doi.org/10.1007/ s00268-013-2133-3)

23 Bukvic BR, Zivaljevic VR, Sipetic SB, Diklic AD, Tausanovic KM \& Paunovic IR. Improvement of quality of life in patients with benign goiter after surgical treatment. Langenbeck's Archives of Surgery 2014 399 755-764. (https://doi.org/10.1007/s00423-014-1221-7)

24 Zivaljevic VR, Bukvic Bacotic BR, Sipetic SB, Stanisavljevic DM, Maksimovic JM, Diklic AD \& Paunovic IR. Quality of life improvement in patients with Hashimoto thyroiditis and other goiters after surgery: a prospective cohort study. International Journal of Surgery 201521 150-155. (https://doi.org/10.1016/j. ijsu.2015.08.001)

25 Lee MC, Park H, Lee BC, Lee GH \& Choi IJ. Comparison of quality of life between open and endoscopic thyroidectomy for papillary thyroid cancer. Head and Neck 201638 E827-E831. (https://doi. org/10.1002/hed.24108)

26 Cramon P, Bonnema SJ, Bjorner JB, Ekholm O, Feldt-Rasmussen U, Frendl DM, Groenvold M, Hegedüs L, Rasmussen ÅK \& Watt T. Quality of life in patients with benign nontoxic goiter: impact of disease and treatment response, and comparison with the general population. Thyroid 201525 284-291. (https://doi.org/10.1089/ thy.2014.0433)

27 Cramon P, Winther KH, Watt T, Bonnema SJ, Bjorner JB, Ekholm O, Groenvold M, Hegedüs L, Feldt-Rasmussen U \& Rasmussen ÅK. Quality-of-life impairments persist six months after treatment of Graves' hyperthyroidism and toxic nodular goiter: a prospective cohort study. Thyroid 201626 1010-1018. (https://doi.org/10.1089/ thy.2016.0044)

28 Sorensen JR, Watt T, Cramon P, Døssing H, Hegedüs L, Bonnema SJ \& Godballe C. Quality of life after thyroidectomy in patients with nontoxic nodular goiter: a prospective cohort study. Head and Neck 201739 2232-2240. (https://doi.org/10.1002/hed.24886)

29 Metallo M, Groza L, Brunaud L, Klein M, Weryha G \& Feigerlova E. Long-term quality of life and pregnancy outcomes of differentiated thyroid cancer survivors treated by total thyroidectomy and I(131) during adolescence and young adulthood. International Journal of Endocrinology 20162016 7586482. (https://doi. org/10.1155/2016/7586482)

30 Kus LH, Hopman WM, Witterick IJ \& Freeman JL. Quality-of-life outcomes in Graves disease patients after total thyroidectomy. Ear, Nose, and Throat Journal 201796 E8-E15. (https://doi. org/10.1177/0145561317096004-501) 
31 Hoftijzer HC, Heemstra KA, Corssmit EP, van der Klaauw AA, Romijn JA \& Smit JW. Quality of life in cured patients with differentiated thyroid carcinoma. Journal of Clinical Endocrinology and Metabolism 200893 200-203. (https://doi.org/10.1210/jc.2007-1203)

32 Scerrino G, Morfino G, Paladino NC, Di Paola V, Amodio E, Gulotta G \& Bonventre S. Does thyroid surgery for Graves' disease improve health-related quality of life? Surgery Today $2013 \mathbf{4 3}$ 1398-1405. (https://doi.org/10.1007/s00595-012-0442-z)

33 Abraham-Nordling M, Wallin G, Lundell G \& Törring O. Thyroid hormone state and quality of life at long-term follow-up after randomized treatment of Graves' disease. European Journal of Endocrinology 2007156 173-179. (https://doi.org/10.1530/eje.1.02336)

34 Sherman SI. Thyroid carcinoma. Lancet 2003361 501-511. (https:// doi.org/10.1016/S0140-6736(03)12488-9)

35 Miyauchi A. Clinical trials of active surveillance of papillary microcarcinoma of the thyroid. World Journal of Surgery $2016 \mathbf{4 0}$ 516-522. (https://doi.org/10.1007/s00268-015-3392-y)

36 Singer S, Lincke T, Gamper E, Bhaskaran K, Schreiber S, Hinz A \& Schulte T. Quality of life in patients with thyroid cancer compared with the general population. Thyroid 201222 117-124. (https://doi. org/10.1089/thy.2011.0139)

37 Massolt ET, van der Windt M, Korevaar TI, Kam BL, Burger JW, Franssen GJ, Lehmphul I, Köhrle J, Visser WE \& Peeters RP. Thyroid hormone and its metabolites in relation to quality of life in patients treated for differentiated thyroid cancer. Clinical Endocrinology 2016 85 781-788. (https://doi.org/10.1111/cen.13101)

38 Husson O, Haak HR, Buffart LM, Nieuwlaat WA, Oranje WA, Mols F, Kuijpens JL, Coebergh JW \& van de Poll-Franse LV. Health-related quality of life and disease specific symptoms in long-term thyroid cancer survivors: a study from the population-based PROFILES registry. Acta Oncologica 201352 249-258. (https://doi.org/10.3109/0 284186X.2012.741326)

39 Gamper EM, Wintner LM, Rodrigues M, Buxbaum S, Nilica B, Singer S, Giesinger JM, Holzner B \& Virgolini I. Persistent quality of life impairments in differentiated thyroid cancer patients: results from a monitoring programme. European Journal of Nuclear Medicine and Molecular Imaging 201542 1179-1188. (https://doi.org/10.1007/ s00259-015-3022-9)

40 Nexo MA, Watt T, Bonnema SJ, Hegedüs L, Rasmussen ÅK, FeldtRasmussen U \& Bjorner JB. Thyroid-specific questions on work ability showed known-groups validity among Danes with thyroid diseases. Quality of Life Research 201524 1615-1627. (https://doi.org/10.1007/ s11136-014-0896-0)

41 Cusano NE, Rubin MR, McMahon DJ, Irani D, Tulley A, Sliney Jr J \& Bilezikian JP. The effect of PTH(1-84) on quality of life in hypoparathyroidism. Journal of Clinical Endocrinology and Metabolism 201398 2356-2361. (https://doi.org/10.1210/jc.2013-1239)

42 Sikjaer T, Moser E, Rolighed L, Underbjerg L, Bislev LS, Mosekilde L $\&$ Rejnmark L. Concurrent hypoparathyroidism is associated with impaired physical function and quality of life in hypothyroidism. Journal of Bone and Mineral Research 201631 1440-1448. (https://doi. org/10.1002/jbmr.2812)

43 Astor MC, Løvås K, Debowska A, Eriksen EF, Evang JA, Fossum C, Fougner KJ, Holte SE, Lima K, Moe RB et al. Epidemiology and health-related quality of life in hypoparathyroidism in Norway. Journal of Clinical Endocrinology and Metabolism $20161013045-3053$. (https://doi.org/10.1210/jc.2016-1477)

44 Bagó AG, Dimitrov E, Saunders R, Seress L, Palkovits M, Usdin TB $\&$ Dobolyi A. Parathyroid hormone 2 receptor and its endogenous ligand tuberoinfundibular peptide of 39 residues are concentrated in endocrine, viscerosensory and auditory brain regions in macaque and human. Neuroscience 2009162 128-147. (https://doi. org/10.1016/j.neuroscience.2009.04.054)

45 Sikjaer T, Rolighed L, Hess A, Fuglsang-Frederiksen A, Mosekilde L $\&$ Rejnmark L. Effects of PTH(1-84) therapy on muscle function and quality of life in hypoparathyroidism: results from a randomized controlled trial. Osteoporosis International 201425 1717-1726.

46 Stojadinovic A, Shaha AR, Orlikoff RF, Nissan A, Kornak MF, Singh B, Boyle JO, Shah JP, Brennan MF \& Kraus DH. Prospective functional voice assessment in patients undergoing thyroid surgery. Annals of Surgery 2002236 823-832. (https://doi.org/10.1097/00000658200212000-00015)

47 Stojadinovic A, Henry LR, Howard RS, Gurevich-Uvena J, Makashay MJ, Coppit GL, Shriver CD \& Solomon NP. Prospective trial of voice outcomes after thyroidectomy: evaluation of patientreported and clinician-determined voice assessments in identifying postthyroidectomy dysphonia. Surgery 2008143 732-742. (https:// doi.org/10.1016/j.surg.2007.12.004)

48 Vicente DA, Solomon NP, Avital I, Henry LR, Howard RS, Helou LB, Coppit GL, Shriver CD, Buckenmaier CC, Libutti SK et al. Voice outcomes after total thyroidectomy, partial thyroidectomy, or nonneck surgery using a prospective multifactorial assessment. Journal of the American College of Surgeons 2014219 152-163. (https://doi. org/10.1016/j.jamcollsurg.2014.03.019)

49 Maertens $\mathrm{K} \&$ de Jong FI. The voice handicap index as a tool for assessment of the biopsychosocial impact of voice problems. $B$-ENT 20073 61-66.

50 Volpato S, Guralnik JM, Fried LP, Remaley AT, Cappola AR \& Launer LJ. Serum thyroxine level and cognitive decline in euthyroid older women. Neurology 200258 1055-1061. (https://doi. org/10.1212/wnl.58.7.1055)

51 Williams MD, Harris R, Dayan CM, Evans J, Gallacher J \& BenShlomo Y. Thyroid function and the natural history of depression: findings from the Caerphilly Prospective Study (CaPS) and a meta-analysis. Clinical Endocrinology 200970 484-492. (https://doi. org/10.1111/j.1365-2265.2008.03352.x)

52 Gussekloo J, van Exel E, de Craen AJ, Meinders AE, Frölich M \& Westendorp RG. Thyroid status, disability and cognitive function, and survival in old age. JAMA 2004292 2591-2599. (https://doi. org/10.1001/jama.292.21.2591)

53 Booth T, Deary IJ \& Starr JM. Thyroid stimulating hormone, free thyroxine and cognitive ability in old age: the Lothian Birth Cohort Study 1936. Psychoneuroendocrinology 201338 597-601. (https://doi. org/10.1016/j.psyneuen.2012.07.018)

54 Ojomo KA, Schneider DF, Reiher AE, Lai N, Schaefer S, Chen H \& Sippel RS. Using body mass index to predict optimal thyroid dosing after thyroidectomy. Journal of the American College of Surgeons 2013 216 454-460. (https://doi.org/10.1016/j.jamcollsurg.2012.12.002)

55 Jin J, Allemang MT \& McHenry CR. Levothyroxine replacement dosage determination after thyroidectomy. American Journal of Surgery 2013205 360-363; discussion 363-364. (https://doi.org/10.1016/j. amjsurg.2012.10.015)

56 Watt T, Cramon P, Hegedüs L, Bjorner JB, Bonnema SJ, Rasmussen ÅK, Feldt-Rasmussen U \& Groenvold M. The thyroidrelated quality of life measure ThyPRO has good responsiveness and ability to detect relevant treatment effects. Journal of Clinical Endocrinology and Metabolism 201499 3708-3717. (https://doi. org/10.1210/jc.2014-1322)
Received 21 July 2019

Revised version received 29 November 2019

Accepted 3 December 2019 